\title{
FREQUENCY AND Q-FACTOR OF THE LOWEST FREQUENCY COMPLEX CONJUGATE POLES ESTIMATION METHOD BASED ON THE CONTROL SYSTEM'S CHARACTERISTIC EQUATION COEFFICIENTS VALUES Dovgopolaya E.A. (Russian Federation) Email: Dovgopolaya348@scientifictext.ru
}

\author{
Dovgopolaya Elena Alekseevna - PhD Student, \\ DEPARTMENT OF ELECTRONIC MEASUREMENT SYSTEMS \\ NATIONAL RESEARCH NUCLEAR UNIVERSITY MEPHI, MOSCOW
}

\begin{abstract}
This paper contains the author's opinion about estimating the systems lowest frequency complex conjugate poles. The proposed method uses the characteristic equation coefficients values to sum up the frequency and q-factor of complex conjugate poles. Based on Routh-Hurwitz stability criterion this evaluating way is applicable to free degree characteristic equation. The proposed method has been tested and endorsed by comparison with the test simulation and physical model experiments for a few common cases.

Keywords: control system, Routh-Hurwitz criterion, characteristic equation, dominant pole, Q-factor, quality analysis, estimation formulas, nonlinear algebraic equation, smooth nonlinear problem solving, complex conjugate roots.
\end{abstract}

\section{МЕТОД ОЦЕНКИ ЧАСТОТЫ И ДОБРОТНОСТИ НАИБОЛЕЕ НИЗКОЧАСТОТНЫХ КОМПЛЕКСНО-СОПРЯЖЕННЫХ ПОЛЮСОВ ПО КОЭФФИЦИЕНТАМ ХАРАКТЕРИСТИЧЕСКОГО УРАВНЕНИЯ СИСТЕМЫ АВТОМАТИЧЕСКОГО РЕГУЛИРОВАНИЯ Довгополая Е.А. (Российская Федерация)}

\author{
Довгополая Елена Алексеевна - аспирант, \\ кафедра электронных измерительных систем, \\ Национальный исследовательский ядерный университет «МИФИ», г. Москва
}

\begin{abstract}
Аннотация: множество методов анализа систем автоматического регулирования используют корневые оценки. В настоящей работе предложен метод оцченки частоты и добротности наиболее низкочастотных комплексно-сопряженных полюсов по коэффициентам характеристического уравнения. Предложенный метод базируется на выполнении критерия устойчивости Рауса-Гурвица и может быть применен для характеристического уравнения произвольной степени. Предложенный метод апробирован путем сравнения с результатами математического и физического моделирования для ряда распространенных частных случаев.
\end{abstract}

Ключевые слова: система автоматического регулирования, критерий Рауса-Гурвица, характеристическое уравнение, доминирующий полюс, добротность, анализ качества, приближенные формуль, нелинейные алгебраические уравнения, решение гладких нелинейных задач, комплексносопряженные корни.

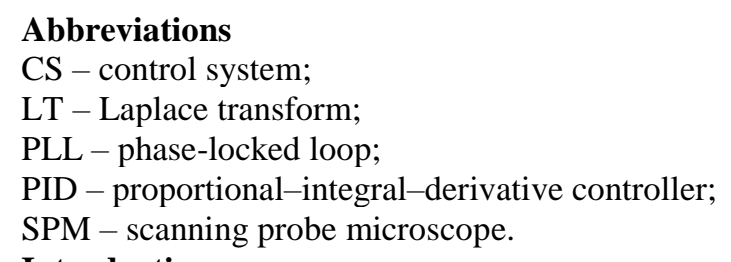

\section{Introduction}

Mathematical formalization of technical systems leads to integrodifferential equations. LT result is the describing model contains of nonlinear algebraic equations. Because of analysis needs there is the common necessity of the high-order algebraic equations root characteristics investigation. The way to estimate the cubic polynomial roots was proposed at [1-3]. The introduced formulas extended for the fourth degree equation roots Q-factor study in case of technical systems analysis [4]. A method of evaluating the roots of the private class of nonlinear algebraic equations with positive coefficients for the case of substantially different roots abs, among which there is at least one pair of complex-conjugate roots, proposed at [5]. All of this methods are particular and somewhat application limited. So the actual task is to extend the above methods application for the more general cases. One of such ways in case of control systems (CS) is reflected by the current paper. There is a method for the frequency and Q-factor estimating by the coefficients of the CS characteristic equation in case of the lowest frequency complex conjugate poles and real root domination below. 


\section{Proposed method}

Routh-Hurwitz stability criterion [6] could be formulated as:

The characteristic equation

$$
a_{0} x^{n}+a_{1} x^{n-1}+a_{2} x^{n-2}+\cdots+a_{n-1} x+a_{n}=0
$$

have no roots in the right-half plane if and only if the leading coefficient is positive $\left(a_{0}>0\right)$ and each of principal minors is positive:

$$
\Delta_{1}>0, \Delta_{2}>0, \ldots, \Delta_{n}>0 .
$$

In case of biquadratic equation

$$
a_{0} x^{2}+a_{1} x+a_{2}=0
$$

Routh-Hurwitz stability criterion met if

$$
a_{0}>0, \Delta_{1}=a_{1}>0, \Delta_{2}=\left|\begin{array}{ll}
a_{1} & a_{0} \\
a_{3} & a_{2}
\end{array}\right|=a_{1} a_{2}>0 .
$$

Thus the complex conjugate roots lets be described by its frequency $\omega_{0}$ and Q-factor $q_{0}$ given by the following formulas

In case of cubic equation

$$
\omega_{0}=\sqrt{\frac{a_{2}}{a_{0}}}, q_{0}=\frac{\sqrt{a_{0} a_{2}}}{a_{1}} .
$$

Routh-Hurwitz stability criterion met if

$$
a_{0} x^{3}+a_{1} x^{2}+a_{2} x+a_{3}=0
$$

$$
a_{0}>0, \Delta_{1}=a_{1}>0, \Delta_{2}=\left|\begin{array}{ll}
a_{1} & a_{0} \\
a_{3} & a_{2}
\end{array}\right|=a_{1} a_{2}-a_{0} a_{3}>0, \Delta_{3}=a_{3}>0 \text {. }
$$

In case of real root domination $[1,8]$ the frequency $\omega_{0}$ and the Q-factor $q_{0}$ of complex conjugate roots may be discovered as

$$
\omega_{0}=\sqrt{\frac{a_{2}}{a_{0}}}, q_{0}=\frac{a_{2} \sqrt{a_{0} a_{2}}}{a_{1} a_{2}-a_{0} a_{3}} .
$$

This result extends to the case of higher orders of the characteristic equation. The authors research has shown that the lowest frequency complex conjugate poles may be estimated by the following simple formulas (in case of real root domination which is appreciate for CS):

$$
\omega_{0}=\sqrt{\frac{a_{2}}{a_{0}}}, q_{0}=\frac{a_{2} \sqrt{a_{0} a_{2}}}{\Delta_{2}} .
$$

Using the above formulas allows the rapid and easy-to-understand CS quality analysis.

\section{Conclusion}

The proposed frequency and Q-factor of the lowest frequency complex conjugate poles estimation method based on the control system's characteristic equation coefficients values is a logical continuation and generalization of the previous works of the authors in the field of short time CS design. The obtained results could be extended for the broadband and pulse amplifiers, active filters, mechanical resonance systems analysis, etc.

The proposed method has been tested and endorsed by comparison with the test simulation and physical model experiments for the following common cases:

- frequency range estimation of active biquadratic section based on operation amplifier chips [7];

- simple regulator's type and parameters validation to ensuring aperiodic transients in CS obeying a mathematical model with cubic characteristic equation [8-9];

- PID tunning in case of synthesis the CS with aperiodic transient [10];

- SPM control system analysis [11-12];

- PLL based on LTC6945 chip simulation [9].

The obtained results used to increase the characteristics of developed measuring equipment (with the participation of NRNU MEPhI Department of Electronic Measurement Systems). 


\section{Acknowledgements}

The work was carried out at the NRNU MEPhI with the support of the grant of the Foundation for Assistance to Small Innovative Enterprises (FASIE) under the contract (agreement) № 11296ГУ/2016 by 07.04.2017.

\section{References / Список литературы}

1. Maslennikov V.V., 2015. Method of Approximate Determination of the Roots of Cubic Equation with Positive Coefficients and Complex-Conjugate Roots. Vestn. NIYaU MIFI 4(2): 179-183.

2. Maslennikov V.V., Avtushko V.P., 2015. Methods for Increasing the Accuracy of Approximate Formulas for the Roots of a Cubic Equation with Complex Conjugate Roots. Vestn. NIYaU MIFI 4(4): 354-358.

3. Maslennikov V.V., 2015. New Method for Solving Algebraic Equations without the Use of Imaginary Numbers. Vestn. NIYaU MIFI 4(6): 554-559.

4. Dovgopolaya E.A., Maslennikov V.V., 2017. The Approximate Determination Complex Conjugate Roots QFactor Method For The Fourth Order Equations With Positive Coefficients. RF-china-science 21: 37-41.

5. Dovgopolaya E.A., 2017. A Method Of Evaluating The Roots Of The Private Class Of Nonlinear Algebraic Equations With Positive Coefficients. Science, Technology and Education 11 (41): 20-25.

6. Richard C. Dorf, Robert H. Bishop, 2001. Modern Control Systems (9th ed.), Prentice-Hall, Upper Saddle River. NJ. USA. Pp. 831.

7. Maslennikov V.V., Dovgopolaya E.A., 2014. The Frequency Range of Operation Amplifier Active Biquadratic Section. «Radiotekhnika» (Radioengineering) 12: 57-63.

8. Maslennikov V.V., Meshcheryakov V.V., Dovgopolaya E.A., 2016. Methods Of Analysis Of Automatic Control Systems Obeying A Mathematical Model With Cubic Characteristic Equation. Automation and remote control 77(12): 2149-2157.

9. Maslennikov V.V., Meshcheryakov V.V., Dovgopolaya E.A., 2018. Conditions of Aperiodic Transient in Control Systems Obeying a Mathematical Model with Cubic Characteristic Equation. International MultiConference on Industrial Engineering and Modern Technologies (FarEastCon), Russia.

10. Maslennikov V.V., Meshcheryakov V.V., Dovgopolaya E.A., 2018. Conditions For Ensuring Aperiodic Transients In Automatic Control Systems With A PID Controller. TOAUTOCJ 10: 9-14.

11. Maslennikov V.V., Meshtcheryakov V.V., Dovgopolaya E.A., 2016. Selection of the Parameters of a PID Controller in the Automatic Control System of a Scanning Probe Microscope. Vestn. NIYaU MIFI 5(3): Pp. 243-245.

12. Dovgopolaya E.A., Maslennikov V.V., Meshcheryakov V.V., 2017. New Approach To Upgrade SPM Control System. Physics, Engineering and Technologies for Biomedicine. The 2nd International Symposium, Russia. 